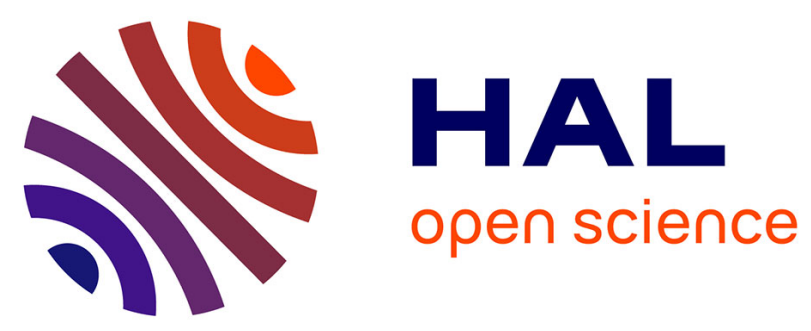

\title{
Rheological, electrical, and dynamic thermomechanical properties: Comparison between multiwall and double-wall carbon nanotubes in polylactide and polyamide 11
}

Zeinab Mousavi, Marie-Claude Heuzey, Musa R Kamal, Emmanuel Flahaut, Pierre J Carreau

\section{To cite this version:}

Zeinab Mousavi, Marie-Claude Heuzey, Musa R Kamal, Emmanuel Flahaut, Pierre J Carreau. Rheological, electrical, and dynamic thermomechanical properties: Comparison between multiwall and double-wall carbon nanotubes in polylactide and polyamide 11. Physics of Fluids, 2021, 33 (11), pp.113103. 10.1063/5.0068537 . hal-03427412

\section{HAL Id: hal-03427412 \\ https://hal.science/hal-03427412}

Submitted on 17 Nov 2021

HAL is a multi-disciplinary open access archive for the deposit and dissemination of scientific research documents, whether they are published or not. The documents may come from teaching and research institutions in France or abroad, or from public or private research centers.
L'archive ouverte pluridisciplinaire HAL, est destinée au dépôt et à la diffusion de documents scientifiques de niveau recherche, publiés ou non, émanant des établissements d'enseignement et de recherche français ou étrangers, des laboratoires publics ou privés. 


\title{
Rheological, electrical and dynamic thermomechanical properties: comparison between multiwall and double-wall carbon nanotubes in polylactide and polyamide 11
}

\author{
Zeinab Mousavi ${ }^{a}$, Marie-Claude Heuzey ${ }^{a}$, Musa R. Kamal ${ }^{b}$, Emmanuel Flahaut ${ }^{c}$, Pierre J. \\ Carreau $^{\text {a* }}$ \\ ${ }^{a}$ Centre for High performance Polymer and Composite Systems (CREPEC), Chemical Engineering Department, \\ Polytechnique Montreal, Montreal, Quebec H3T 1J4, Canada \\ ${ }^{\mathrm{b}}$ CREPEC, Chemical Engineering Department, McGill University, Montreal, Quebec H3A 2B2, Canada \\ ${ }^{\mathrm{c}}$ CIRIMAT Site UPS, UMR CNRS 5085, Université Paul Sabatier, Toulouse, France \\ *Corresponding author : pcarreau@polymtl.ca
}

\begin{abstract}
In this study multiwall carbon nanotubes (MWCNTs) and double-wall carbon nanotubes (DWCNTs) have been dispersed in polylactide (PLA) and polyamide 11 (PA11) using an internal mixer. Rheological characterization confirmed the formation of carbon nanotube (CNT) networks in PLA and PA11 attributed to well dispersed CNTs in the respective matrices. A lower rheological percolation threshold of PLA/MWCNT nanocomposites (less than 0.5 wt. \%) compared to PA11/MWCNT nanocomposites (about 2 wt. \%) confirmed the greater affinity of CNTs with PLA. The threshold for DWCNTs was below $0.5 \mathrm{wt}$ \% in PLA and between 0.5 and 1 wt. \% in PA11. PLA-based nanocomposites also showed higher electrical conductivity values compared to PA11-based nanocomposites. Nanocomposites containing DWCNTs exhibited higher electrical conductivities compared to those containing MWCNTs due to the higher aspect ratio of DWCNTs. Dynamic mechanical thermal analysis (DMTA) showed enhanced storage modulus values and reduced damping behavior with increasing content of CNTs for both polymers.
\end{abstract}

Keywords

Nanocomposites, PLA, PA11, Carbon nanotubes, MWCNT, DWCNT, Rheology 


\section{Introduction}

Environmental concerns regarding the production of petroleum-based polymers and accumulation of their waste in the natural ecosystem have resulted in increasing interest in using biobased and biodegradable polymers. Polylactide (PLA) and polyamide 11 (PA11) are both derived from renewable resources. PLA is manufactured by polymerization of lactic acid or lactide, which is obtained by fermentation of starch/sugar extracted from agricultural products. ${ }^{1}$ In addition, it is also biodegradable. PA11 is based on castor oil. It is not biodegradable, but, due to low generation of $\mathrm{CO}_{2}$ emission during its production, it has less negative impacts on the environment than its petroleum based counterparts. ${ }^{2}$

PLA has high stiffness and strength. However, its low ductility, slow crystallization and low heat-resistance limit its applications. On the other hand, PA11 has higher ductility and better thermomechanical performance, compared to PLA. Several techniques have been used for improving the ductility and thermal properties of PLA. These techniques include blending with another polymer, which possesses the complementary characteristics ${ }^{3,4}$ and incorporating nanoparticles. $^{5,6}$ Adding nanoparticles such as CNTs improves the thermal and mechanical properties of PLA. They would also impart added functionality to the material, i.e., electrical and thermal conductivity. ${ }^{7}$ Incorporating CNTs into these bio-based polymers enables the production of materials that can be used for electrostatic dissipation and electromagnetic interference shielding. Their application as liquid sensors has also been reported where the sensing properties are associated with a change in the electrical conductivity of these nanocomposites when exposed to a specific liquid. ${ }^{8}$

While single wall carbon nanotubes (SWCNTs) can be described by a single graphene layer rolled over itself, MWCNTs are composed of concentric carbon nanotubes arranged like Russian dolls, with a spacing of $0.34 \mathrm{~nm}$ between each other. ${ }^{9}$ DWCNTs, with only one inner and one outer wall, are at the interface between these two categories of carbon nanotubes, combining advantages of both such as the high flexibility and mechanical strength of SWCNTs together with the protection of the inner wall and the much larger ratio of electrically conducting 
nanotubes. ${ }^{10}$ DWCNTs are expected to possess higher flexural modulus than SWCNTs due to the two walls and higher toughness than MWCNTs. ${ }^{11}$ Dispersing nanoparticles in polymers is hindered by the inherent thermodynamics drive of nanoparticles/nanotubes to form agglomerates/bundles. The efficiency of nanoparticles in improving the properties of a polymer matrix depends on the quality of the dispersion in the matrix, which is a function of the level of interaction between the polymer chains and nanoparticles or their affinity. Melt mixing is the industrially preferred method for preparation of nanocomposites and it is more environmentally friendly (solvent free) compared to other methods such as solution casting and in-situ polymerization. It utilizes high shear/elongational forces and high temperatures to disperse the nanoparticles in a polymer. It is generally less effective than solution casting and is limited to lower contents of nanoparticles due to high viscosities at higher nanoparticle contents. The main steps involved in dispersing CNTs in a polymer matrix include wetting of primary agglomerates by the polymer and infiltration of polymer chains into the primary agglomerates followed by rupture and erosion and the distribution of individualized nanotubes into the matrix. ${ }^{12}$

The surface energies between the nanotubes and polymer chains determines the level of interactions between these components, their chemical affinity and interfacial adhesion. Better affinity between the carbon nanotubes and the polymer matrix enhances the quality of dispersion of the nanotubes in the polymer. Improved dispersion yields a more significant effect on the rheological, mechanical and electrical properties of the polymer/CNT nanocomposites. Morphological characterization for evaluating the nanotube dispersion in the polymer is required over a range of length scales including optical microscopy and scanning and transmission electron microscopy. Rheological characterization of nanocomposites also provides insight into the microstructure of the material.

Several publications on the dispersion of CNTs in PLA exist in the literature. Surface modification of MWCNTs for improved CNT dispersion in PLA was reported. ${ }^{13-15}$ Carboxylic and hydroxyl functionalized CNTs and purified CNTs were dispersed in PLA via melt blending. Carboxylic functionalized CNTs allowed for the best dispersion state according to transmission electron microscopy (TEM) analysis and rheological characterization, while still some bundles were present. ${ }^{16} \mathrm{Wu}$ et al. ${ }^{17}$ studied the effect of CNT aspect ratio on the formation of percolation networks in PLA/CNT nanocomposites. High and low aspect ratio carboxylic functionalized 
CNTs were added to PLA. The nanocomposites containing the higher aspect ratio CNTs yielded a lower rheological percolation threshold. In another study, PLA-grafted CNTs were obtained by reaction between acrylic acid grafted PLA and hydroxyl functionalized CNTs ${ }^{18}$; these authors compared the dispersion of unmodified and hydroxyl functionalized CNTs in the modified PLA. The latter showed a better dispersion, but the presence of some agglomerates was reported above 3 wt. $\%$ CNTs. $^{14}$

In another study, PLA and CNTs were mixed without chemical modification by generating hybrid crystalline fibrils (shish) in which the extended polymer chains cover the CNTs using multi stage stretching extrusion. ${ }^{19}$ Significant enhancements in elongation at break, strength and modulus were observed compared to un-stretched PLA/CNT nanocomposites. Villmow et al. ${ }^{20}$ prepared PLA/CNT nanocomposites through melt mixing and diluting a masterbatch via a twinscrew extruder. Higher screw rotation speeds and a screw profile containing mainly mixing elements improved the dispersion of CNTs in the PLA. A series of diluted nanocomposites from the masterbatch prepared under optimized extrusion conditions showed no agglomerates of diameter larger than $5 \mu \mathrm{m}$ by light microscopy, an electrical percolation threshold below $0.5 \mathrm{wt}$. $\%$ CNTs and electrical conductivity $(\sigma)$ of $3 \times 10^{-3}{\mathrm{~S} . \mathrm{cm}^{-1}}$ at $0.5 \mathrm{wt} . \%$ CNTs.

Huang et al. ${ }^{21}$ prepared PA11/MWCNT nanocomposites by melt mixing in an internal mixer. An acceptable dispersion of MWCNTs was observed via scanning electron micrographs. The

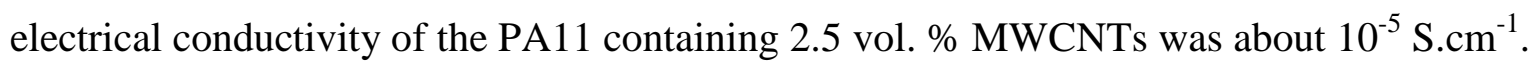

Ha et al. ${ }^{22}$ compared the dispersion of MWCNTs in various polyamides including PA6, PA11 and PA12. Polyamides with longer hydrophobic methylene groups in the repeat unit chains showed lower surface resistivities. However, the molecular weight of these polyamides were not comparable.

Agglomerates of longer or thinner nanotubes are more challenging to disperse in a polymer. This is explained by higher strength of their initial agglomerates, due to much higher surface area and stronger interactions between the tubes compared to shorter nanotubes of larger diameter. Longer tubes also tend to have more entanglements between them. ${ }^{23}$ On the one hand, the dispersion of DWCNTs is more challenging than MWCNTs because the former have a much larger specific surface area, and thus they have a stronger tendency to form bundles and agglomerates in polymer matrices. On the other hand, based on their higher aspect ratios, a more significant 
effect on the rheological and electrical properties is expected. Due to a larger specific surface area for stress transfer at the interface when a good dispersion and adhesion are achieved, hence, DWCNTs are better candidates for reinforcing polymers compared to MWCNTs. ${ }^{24}$

The literature on DWCNT/polymer nanocomposites is scarce. Some publications on DWCNTs (or SWCNTs) in various matrices other than PLA and PA11 and for different preparation techniques are briefly discussed here.

Pristine and modified SWCNTs by styrene maleic anhydride copolymer were melt mixed with PA12. The improved dispersion for modified SWCNTs was confirmed by DMTA and mechanical characterization, but the electrical conductivity was compromised due to coverage of SWCNTs by a polymer layer. No comparison with MWCNTs was made. ${ }^{25}$ Gojny et al., comprehensively studied the effect of MWCNTs, DWCNTs and SWCNTs and their modification on the dispersion of CNTs and on the mechanical properties of epoxy/CNT nanocomposites prepared by calendaring. ${ }^{24}$ Nanocomposites containing amino-functionalized DWCNTs at 0.5 wt. \% demonstrated the most significant improvements in strength $(+10 \%)$, stiffness $(+15 \%)$ and fracture toughness $(+43 \%)$. In another study, DWCNTs were dispersed in an epoxy using sonication and mechanical stirring. The electrical percolation threshold was between 0.2 and 0.4 wt. \%. The electrical conductivity of nanocomposites containing 2.5 wt. \%

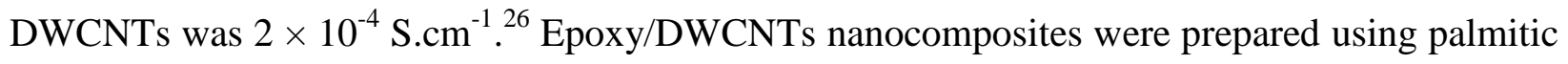
acid as a surfactant to improve the dispersion of the DWCNTs. Spectroscopic Raman maps were recorded to evaluate the uniformity of the dispersed DWCNTs in the epoxy. ${ }^{27}$ Tishkova et al., studied the electrical conductivity of DWCNTs dispersed in a polyether ether ketone (PEEK) matrix. ${ }^{28}$ Nanocomposites were prepared by dispersing the CNTs and PEEK powder in acetone followed by probe sonication and evaporation of the acetone. The electrical percolation threshold was in the range of $0.2-0.3$ wt. $\%$ and, at 2 wt. $\%$, the electrical conductivity was $3 \times 10^{-2}{\mathrm{~S} . \mathrm{cm}^{-1}}^{\text {. }}$

In summary, there are several publications on the properties of PLA containing surface-modified and unmodified MWCNTs prepared through various methods. However, there are few publications on evaluating the properties of PA11/MWCNT nanocomposites prepared by similar methods and the literature is scarce on the dispersion of DWCNTs in polymers through melt mixing. In this work, we evaluate and compare the dispersion of MWCNTs and DWCNTs in PLA and PA11 prepared under identical processing conditions. We focus on the rheological, 
electrical and dynamic thermomechanical properties to obtain a better understanding of the relative affinity of CNTs to these polymers and of the effect of the CNT aspect ratio on nanocomposite properties.

\section{Experimental}

\section{Materials}

PLA 3001D with a melt flow rate (MFR) of $22 \mathrm{~g} / 10 \min \left(210^{\circ} \mathrm{C}, 2.16 \mathrm{~kg}\right)$, melting temperature of $165{ }^{\circ} \mathrm{C}$ and density of $1.24 \mathrm{~g} / \mathrm{cm}^{3}$ was provided by NatureWorks LLC (Minnetonka, MN, USA). PA11 Rilsan LMFO with a melting temperature of $190{ }^{\circ} \mathrm{C}$ and density of $1.02 \mathrm{~g} / \mathrm{cm}^{3}$ was provided by Arkema (King of Prussia, PA, USA). MWCNTs were purchased from Cheap Tubes Inc. (Grafton, VT, USA). These nanotubes were prepared by a catalytic chemical vapor deposition process (CCVD). Their specifications according to the manufacturer are: 10-20 nm diameter, 10-30 $\mu \mathrm{m}$ length, $233 \mathrm{~m}^{2} / \mathrm{g}$ specific surface area and purity greater than $95 \mathrm{wt} \%$. DWCNTs were prepared by a CCVD process at CIRIMAT in Paul Sabatier University, France. ${ }^{29}$ DWCNTs have outer diameters in the $1-3 \mathrm{~nm}$ range, $900-1000 \mathrm{~m}^{2} / \mathrm{g}$ specific surface area and purity greater than 90 wt. \% (typically between 90 and $92-93$ wt.\%, with ca. 4 wt.\% of Co, 1 wt.\% of Mo and the rest of oxygen). Measuring the length of the DWCNTs is challenging because these nanotubes are largely entangled and have a strong tendency to form long bundles of 3-30 $\mathrm{nm}$ in diameter that could reach up to $100 \mu \mathrm{m}$.

\section{Nanocomposite preparation}

PLA was initially dried in a vacuum oven at $60{ }^{\circ} \mathrm{C}$ overnight and PA11, MWCNTs and DWCNTs were dried at $80{ }^{\circ} \mathrm{C}$ overnight. Nanocomposites were prepared using an internal mixer, DDRV501 Brabender (C.W. Brabender Instruments Inc., South Hackensack, NJ, USA) at $200{ }^{\circ} \mathrm{C}$, under a nitrogen atmosphere at a mixing speed of $90 \mathrm{RPM}$ and a mixing time of $8 \mathrm{~min}$. Disks of $25 \mathrm{~mm}$ diameter and $1.5 \mathrm{~mm}$ thickness were compression molded at $200{ }^{\circ} \mathrm{C}$ under nitrogen for $11 \mathrm{~min}$ followed by $3 \mathrm{~min}$ at room temperature. These samples were used for rheological and morphological characterization. The compressive force was gradually increased to $29 \mathrm{kN}$. Samples were dried before each step to prevent the hydrolytic degradation of the 
polymers. Samples for DMTA and electrical resistivity measurements were prepared under similar conditions. The nomenclature indicates the acronym of the matrix followed by the type of carbon nanotube and its content in wt. \%. For example, PLA-DWCNT2 indicates 2 wt. \% of DWCNTs incorporated into PLA. CNT contents in PLA and PA11 were 0.2, 0.5, 1, 2, 3 and 5 wt. $\%$ and $0.2,1,2,3$ and 5 wt. \%, respectively. Considering the density of CNTs, namely 2.1 g.cm ${ }^{-3}$, these values correspond to $0.1,0.3,0.6,1.1,1.7$ and 2.7 vol. \% in PLA and 0.1, 0.5, 0.9, 1.4 and 2.3 vol. \% in PA11. It should be noted that the content of CNTs in PA11 in vol. \% are slightly lower than their content in PLA.

\section{Characterization}

\section{Morphology}

Scanning electron microscopy (SEM) was carried out on nanocomposites using a field emission scanning electron microscope (FE-SEM JSM 7600F, JEOL, Tokyo, Japan) operating at $5 \mathrm{kV}$. Samples for SEM were cryo-fractured in liquid nitrogen and a $20 \mathrm{~nm}$ chromium coating was deposited on the samples. Dispersion of CNTs in the polymer matrices at the nanoscale were evaluated using a JEM 2100F, JEOL, (Tokyo, Japan) transmission electron microscope (TEM). Ultra-thin sections were cut for TEM using an ultra-microtome Ultracut FC microtome (Leica Microsystems, Wetzlar, Germany) with a diamond knife. For measuring the length of MWCNTs using TEM, a dilute suspension of MWCNTs (0.1 wt. \%) in an aqueous solution of sodium dodecyl sulphate was prepared. ${ }^{30,31}$ The samples were sonicated using an ultrasonic bath (FS30, 100 Watts, Fischer Scientific, Pittsburg, PA, USA) for less than 5 minutes. Immediately after the sonication, the TEM grids were dipped in the solution then the excess solution was removed using a tissue paper. The observation was carried out the same day, after a few hours at the latest, so the samples can be considered as dry. ImageJ software ${ }^{32}$ was used for quantitative analysis of the images.

\section{Rheometry}

The rheological properties of the neat polymers and nanocomposites in the linear viscoelastic range were measured using a stress controlled MCR302 rheometer (Anton Paar, Graz, Austria) at $200{ }^{\circ} \mathrm{C}$ under nitrogen. A parallel plate flow geometry was used. Time sweep tests were carried out to ensure the thermal stability of the neat polymers and nanocomposites during the small 
amplitude oscillatory shear (SAOS) experiments. The SAOS experiments were carried out between 0.1 and $100 \mathrm{rad} / \mathrm{s}$.

\section{Electrical resistivity measurements}

The volume electrical resistivity of the samples was determined by measuring the DC resistance across the sample thickness using a Keithley 6517B electrometer/high resistance meter (Keithley instruments, Cleveland, OH, USA) or an Agilent 34401 A 6 1/2 digital multimeter (Keysight Technologies, (formerly Agilent Technologies), Santa Rosa, CA, USA) connected with a twopoint probe. For samples with high resistance, measurements were carried out using the Keithley 6517B electrometer connected to a Keithley 8009 resistivity text fixture (Keithley instruments, Cleveland, OH, USA). $60 \times 5 \times 0.6 \mathrm{~mm}^{3}$ stripes were used for the measurements. $65 \times 65 \times 0.6$ $\mathrm{mm}^{3}$ sheets were used for the measurements with the Keithley 8009 resistivity test fixture. Samples were dried before the measurements and the surface of the specimens were wiped with ethanol before the tests. The voltage for the measurements was adjusted in the $1-100 \mathrm{~V}$ range depending on the electrical resistivity of the samples. The electrical resistivity of a minimum of three replicates was measured for each sample. The measured volume resistances $\left(R_{v}\right)$ were converted to volume resistivity $\left(\rho_{v}\right)$ using the equation: $\rho_{v}=R_{v} \times A / t$ where $A$ is the effective sample area and $t$ is the thickness. The electrical conductivity $(\sigma)$ is the inverse of the volume resistivity.

\section{Dynamic mechanical thermal analysis (DMTA)}

DMTA was carried out on the nanocomposite samples using DMA 2980 analyzer (TA Instruments, New Castle, DE, USA). Bars of $3.2 \mathrm{~mm}$ thick, 12.7 width and $60.5 \mathrm{~mm}$ length were tested in a dual cantilever bending mode at a strain amplitude of $25 \mu \mathrm{m}$ and frequency of $1 \mathrm{~Hz}$. The temperature increased up to $140{ }^{\circ} \mathrm{C}$ at $5{ }^{\circ} \mathrm{C} / \mathrm{min}$ rate. At least four replicates were tested for each sample.

\section{Results and discussion}

\section{Morphology}

Figures 1a and $\mathrm{b}$ show TEM images of the MWCNTs for a dilute suspension of MWCNTs (0.1 wt. \%) in an aqueous solution of sodium dodecyl sulphate for two different scales. The 
length distribution of these MWCNTs, considering their bent morphology, is presented in Figure $2 \mathrm{~b}$. When exposed to ultrasonication in a bath for a short time, the length of a large population is between $0.5 \mu \mathrm{m}$ and $3.5 \mu \mathrm{m}$ (measured for 120 nanotubes). Figure $1 \mathrm{~b}$ shows a single nanotube with an inner diameter of $10 \mathrm{~nm}$ and an outer diameter of $40 \mathrm{~nm}$ (about 40 concentric layers). A layer of SDS on the MWCNTs in some of the TEM images can be observed; however, it can clearly be distinguished from the MWCNTs due to a good contrast and, hence, it did not affect the diameter measurements. Figure $2 \mathrm{a}$ presents the distribution of the MWCNT diameter measured for 265 nanotubes. Their diameter is in the 10-45 $\mathrm{nm}$ range and a small percentage between 50 and $70 \mathrm{~nm}$. The largest percentage is in the $20-25 \mathrm{~nm}$ range resulting in aspect ratios in the range of 11-350. The morphology of DWCNTs, which have a much smaller diameter and longer length compared to MWCNTs, is presented in Figures 1c and d. Single tubes and bundles of a few DWCNTs are observed in Figure 1d.

The quality of the dispersion of the carbon nanotubes in the polymer matrices was evaluated using SEM. A good dispersion is characterized by the good separation of the nanotubes into individual tubes, or at least individual small-diameter bundles. Agglomerates consist of single tubes, bundles, or both. ${ }^{33}$ A system is well distributed, but not well dispersed when the nanotube agglomerates or bundles are uniformly dispersed in the matrix. The SEM micrograph of PLAMWCNT5 nanocomposites indicates well dispersed and well distributed MWCNTs in the PLA (Figure 3a). Figures $3 \mathrm{~b}$ and $\mathrm{c}$ present micrographs of the PA11-MWCNT5 nanocomposites at two positions. The concentration in MWCNT appears higher in Figure $3 \mathrm{c}$ than in $3 \mathrm{~b}$, indicating less uniformly distributed MWCNTs in PA11 and thus a lower quality of the dispersion compared to PLA.

The dispersion of DWCNTs in a polymer matrix is much more difficult to achieve compared to MWCNTs, due to their larger aspect ratio and a strong tendency to form bundles. In the SEM micrographs of nanocomposites containing DWCNTs (Figures 4a-c), longer tubes compared to MWCNTs are observed and they appear to be present in more agglomerated form. Figures $4 \mathrm{~b}$ and 4c compare the PA11/DWCNT2 nanocomposite at two positions, showing an agglomerate in Figure 4c.

The TEM images of PLA-MWCNTs nanocomposites at $2 \mathrm{wt} . \%$ and 5 wt. \% (Figures 5a and b, respectively) suggest a well dispersed state with the presence of many individual tubes (with 
diameters between 10 and $20 \mathrm{~nm}$, a smaller percentage between 20 and $30 \mathrm{~nm}$ and very few between 30 and $40 \mathrm{~nm}$ ) along with a few small agglomerates with diameters less than $0.3 \mu \mathrm{m}$ as measured by the ImageJ software. Figures $5 \mathrm{c}$ and $5 \mathrm{~d}$ show image of PLA-DWCNT2 at two positions where the DWCNTs in the PLA have diameters between 2 and $6 \mathrm{~nm}$, hence bundles of very few nanotubes.
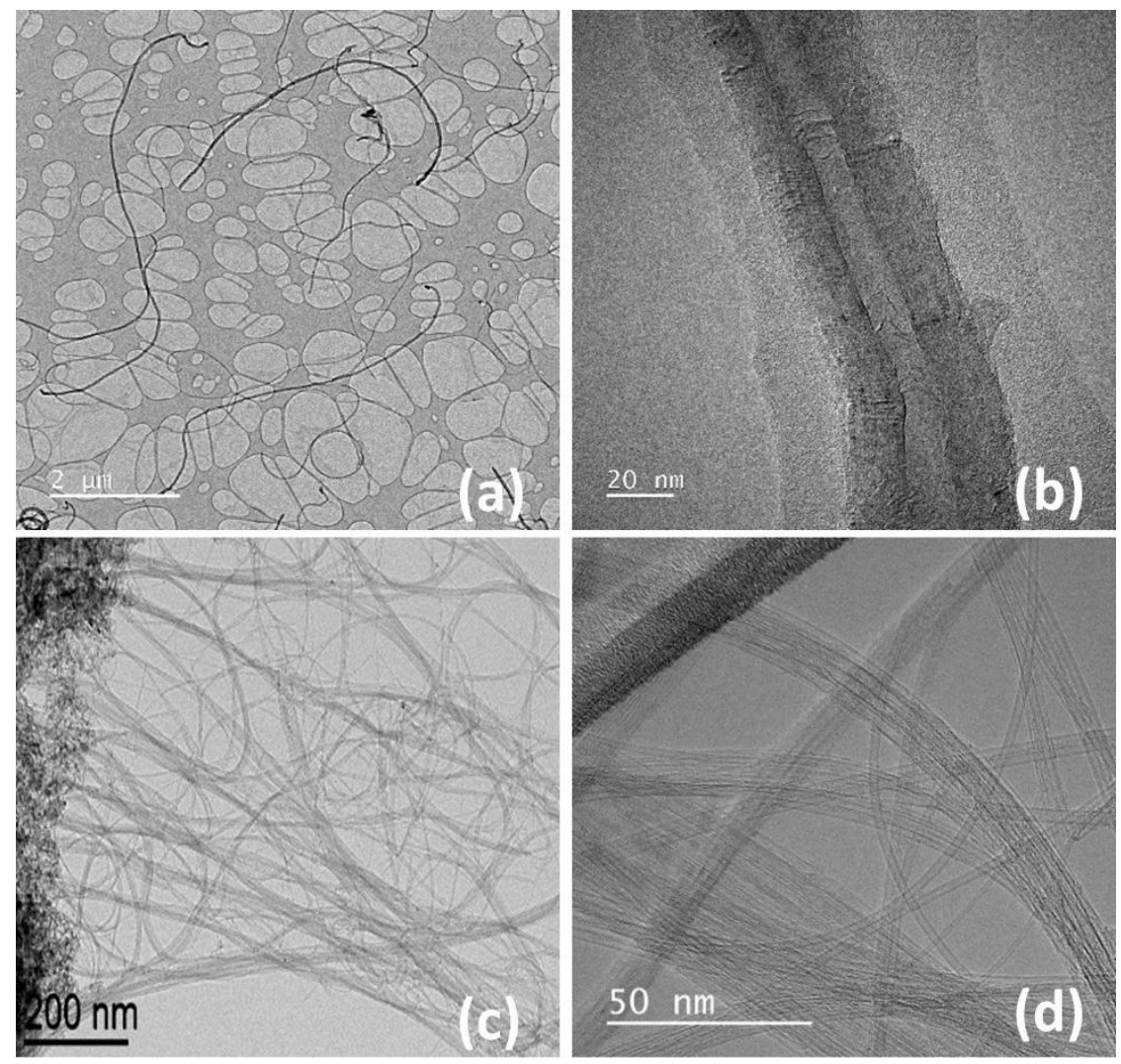

Figure 1. TEM images of (a-b) MWCNTs and (c-d) DWCNTs ${ }^{29}$. 

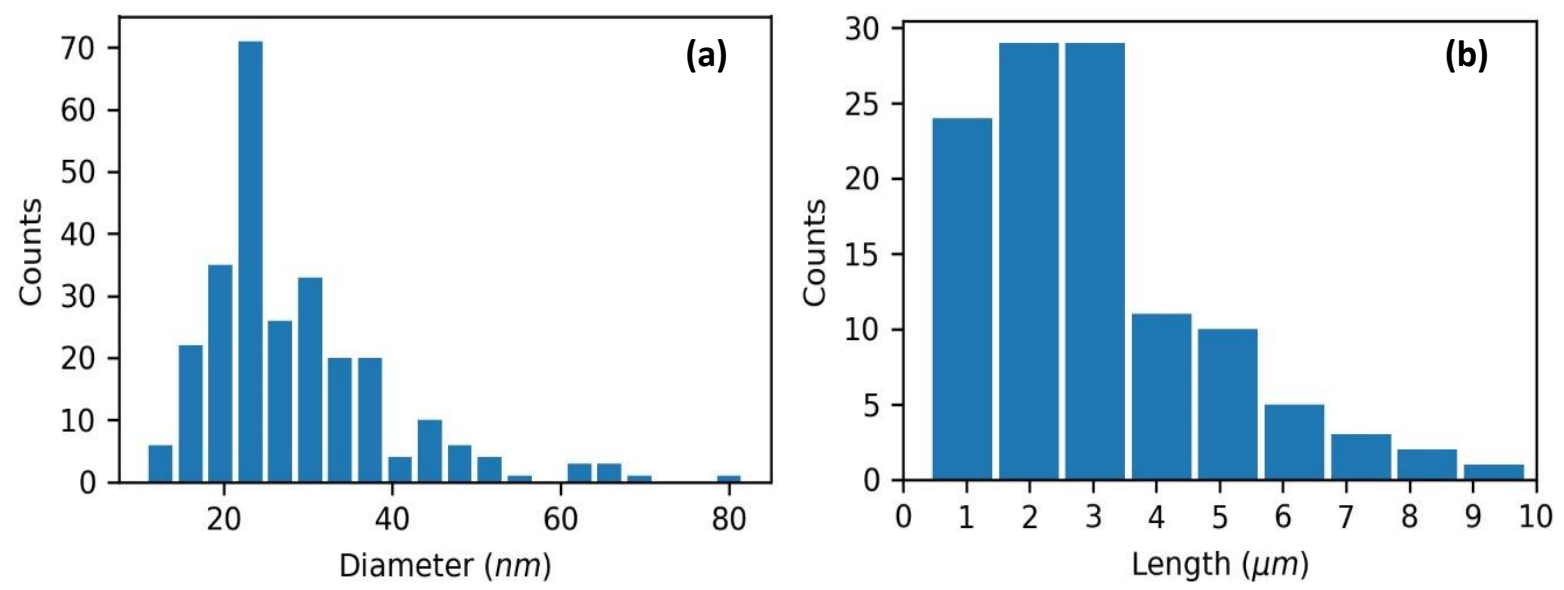

Figure 2. (a) Diameter and (b) length distribution of pristine MWCNTs.
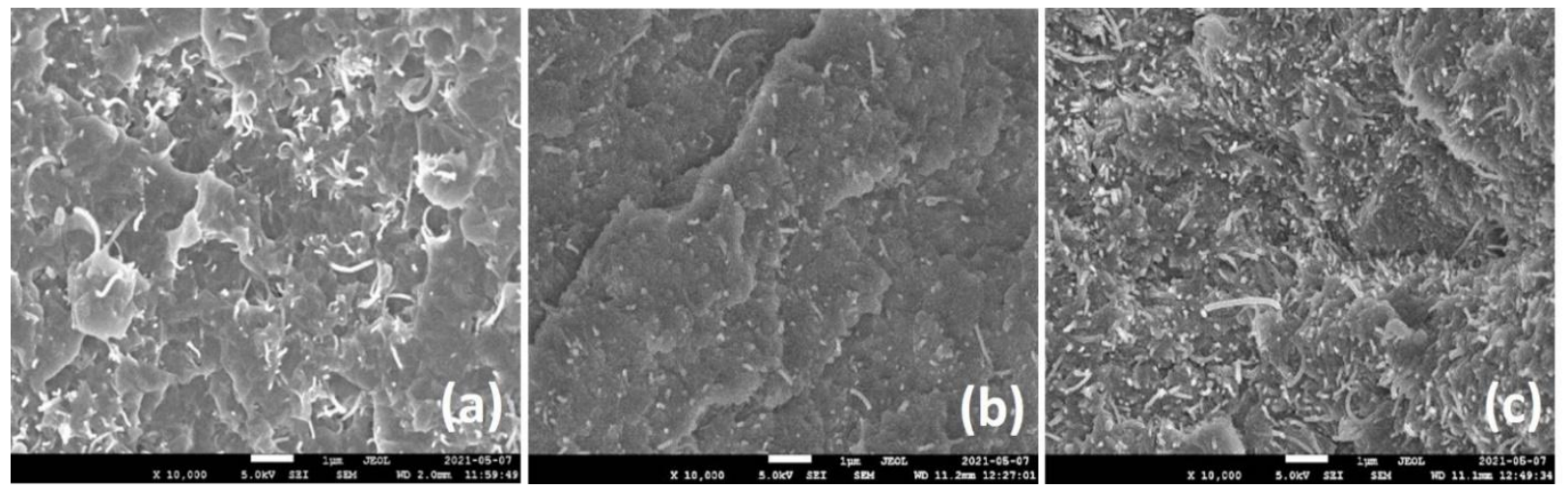

Figure 3. SEM micrographs of (a) PLA-MWCNT5 and (b-c) PA11-MWCNT5. Scale bars are $1 \mu \mathrm{m}$.
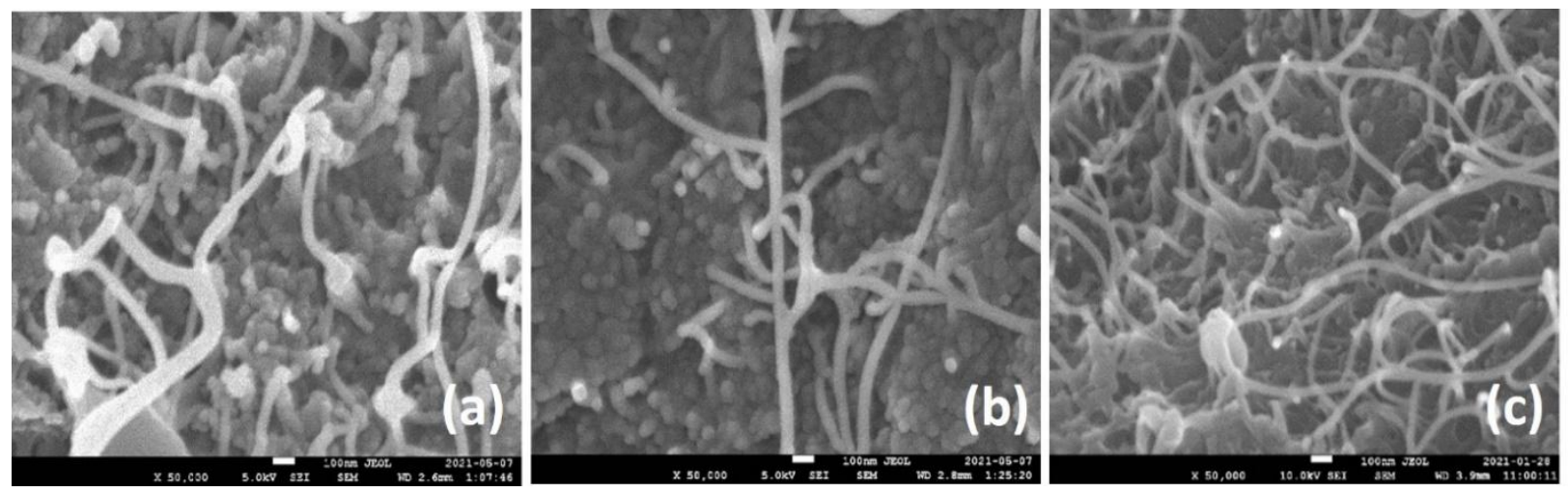
Figure 4. SEM micrographs of (a) PLA-DWCNT2 and (b-c) PA11-DWCNT2. Scale bars are $100 \mathrm{~nm}$.
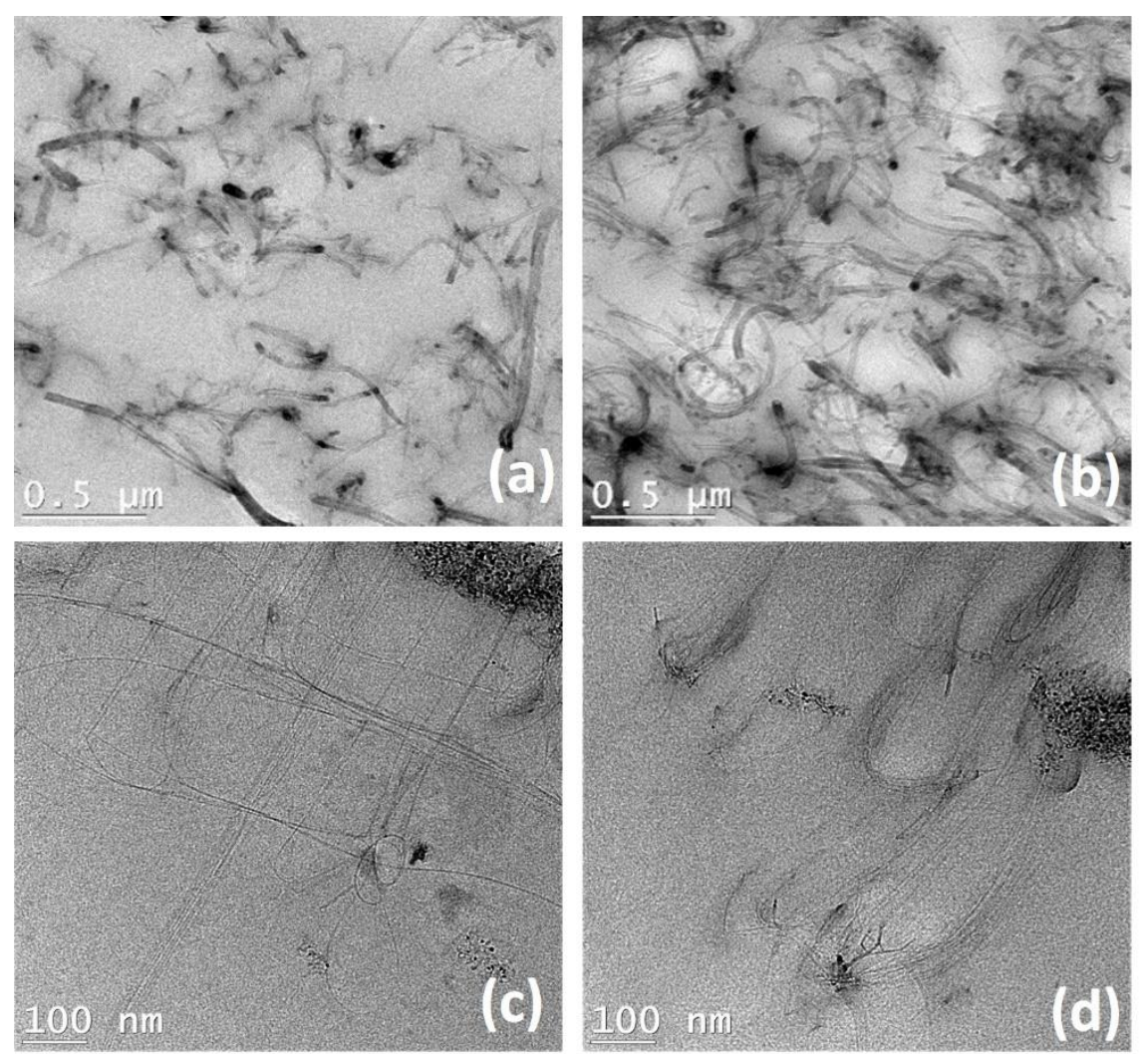

Figure 5. TEM images of (a) PLA-MWCNT2 (b) PLA-MWCNT5 and (c-d) PLA-DWCNT2.

\section{Hansen solubility parameters (HSP)}

The HSP theory defines the cohesive energy density of a chemical and its neighboring media based on the contributions from dispersive, polar and hydrogen-bonding interactions ${ }^{34}$ and each chemical may be described by $\delta_{D}, \delta_{P}$ and $\delta_{H}$ which are the dispersive, polar and hydrogen bonding components of the HSP, respectively. These parameters may be obtained for many solvents and polymers from a database available in HSPiP software package. ${ }^{35}$ An indirect method for determining the unknown HSP values is through affinity tests between the chemical 
and solvents with known HSP values. Based on the idea of "like seeking like", a shorter distance - defined below - between HSP of the material and solvent specifies higher affinity. The distance between the HSP of two materials is expressed by the following equation: ${ }^{34}$

$R_{a}=\sqrt{4\left(\delta_{D 1} \delta_{D 2}{ }^{2}+\left(\delta_{P 1}-\delta_{P 2}\right)^{2}+\left(\delta_{H 1} \delta_{H 2}\right)^{2}\right.}$

The HSP of nanoparticles can be used to predict their affinity and dispersion quality in solvents and polymers. A smaller distance between the HSP of components of a nanocomposite i.e. matrix and nanoparticles means a better dispersion of the nanoparticle in that matrix and better interaction, thus a more thermodynamically favored state. ${ }^{36}$ Here we estimated the HSP values of PA11 based on the HSP values of PA11 good solvents (Table I). These solvents were mentioned in the safety data sheet of PA11 (Rilsan LMFO, Arkema).

Table I. HSP values of good solvents for PA11 (Rilsan, LMFO). ${ }^{35}$

\begin{tabular}{lccc}
\hline Solvent & $\boldsymbol{\delta}_{\boldsymbol{d}}\left(\mathbf{M P a}^{\mathbf{1 / 2}}\right)$ & $\boldsymbol{\delta}_{\boldsymbol{p}}\left(\mathbf{M P a}^{\mathbf{1} / 2}\right)$ & $\boldsymbol{\delta}_{\boldsymbol{H}}\left(\mathbf{M P a}^{\mathbf{1} / 2}\right)$ \\
\hline m-cresol & 18.5 & 6.5 & 13.7 \\
\hline phenol & 18.5 & 5.9 & 14.9 \\
\hline Benzyl alcohol & 18.4 & 6.3 & 13.7 \\
\hline $\begin{array}{l}\text { Formic acid } \\
\text { concentrated) }\end{array}$ & 14.6 & 10.0 & 14.0 \\
\hline
\end{tabular}

The HSP values of PA11 based on the solvents given in Table I as good solvents and methanol as a bad solvent were estimated using the HSPiP software ${ }^{35}$ to be: $\left\{\delta_{d}: 19, \delta_{p}: 6.5\right.$ and $\left.\delta_{H}: 13.7\right\}$ $\mathrm{MPa}^{1 / 2}$. Formic acid was not considered in the estimation of PA11 HSP values because its HSP values are farther from the other three solvents. We note that the limited number of solvents considered might result in inaccuracy of the estimated HSP values.

Table II shows the HSP values of PLA, PA12 (close to PA11), PA11, MWCNTs and DWCNTs and the $R_{a}$ values of PLA/MWCNT and PA11/MWCNT pairs. PLA 1 and $\mathrm{PLA}_{2}$ correspond to two sets of HSP values reported in the HSPiP software database for PLA. PA1 $11_{1}$ corresponds to the HSP values for PA11. ${ }^{35}$ PA11 2 correspond to the values estimated above. As can be seen in 
Table II, the $R_{a}$ distance between the HSP values are higher for PA11/CNT pairs than PLA/CNT pairs, indicating a better affinity of CNTs for PLA as compared to PA11. 
Table II. HSP values of PLA, PA12, PA11 ${ }^{35}$ and MWCNT and DWCNTs ${ }^{37}$.

\begin{tabular}{|c|c|c|c|c|c|}
\hline & $\begin{array}{c}\boldsymbol{\delta}_{d} \\
\left(\mathbf{M P a}^{1 / 2}\right)\end{array}$ & $\begin{array}{c}\boldsymbol{\delta}_{p} \\
\left(\mathbf{M P a}^{1 / 2}\right)\end{array}$ & $\begin{array}{c}\delta_{H} \\
\left(\mathbf{M P a}^{1 / 2}\right)\end{array}$ & $\begin{array}{c}R_{a}(\text { Polymer/MWCNT }) \\
\left(\mathrm{MPa}^{1 / 2}\right)\end{array}$ & $\begin{array}{c}R_{a}(\text { Polymer/DWCNT }) \\
\left(\mathrm{MPa}^{\mathbf{1} 2}\right)\end{array}$ \\
\hline PLA $_{1}$ & 18.6 & 9.7 & 6.0 & 3.5 & 2.9 \\
\hline $\mathbf{P L A}_{2}$ & 18.5 & 8.0 & 7.0 & 2.8 & 2.6 \\
\hline PA12 & 18.5 & 8.1 & 9.1 & 4.4 & 4.3 \\
\hline PA11 $_{1}$ & 17.0 & 4.4 & 10.6 & 7.5 & 7.8 \\
\hline PA11 $_{2}$ & 19.0 & 6.5 & 13.7 & 8.3 & 8.5 \\
\hline MWCNT & 19.5 & 6.7 & 5.5 & - & - \\
\hline DWCNTs & 19.4 & 7.4 & 5.3 & - & - \\
\hline
\end{tabular}

\section{Rheology}

The complex viscosity $\left(\eta^{*}\right)$ and storage modulus $\left(G^{\prime}\right)$ of PLA-MWCNT and PA11-MWCNT nanocomposites obtained from SAOS measurements at $200{ }^{\circ} \mathrm{C}$ are presented in Figures 6a-d. The neat PLA exhibits a Newtonian viscosity plateau at lower frequencies and a weak shearthinning behavior at higher frequencies. The storage modulus, $G^{\prime}$, is increasing as a function of frequency with a slope of 2 on the log-log plot of Figure 6b, as expected from the terminal behavior of a polymer. ${ }^{38}$ With increasing content of MWCNTs a significant increase in $\eta^{*}$ (500 to $10^{6} \mathrm{~Pa}$.s at $0.1 \mathrm{rad} / \mathrm{s}$, hence 4 orders of magnitude, by adding $5 \mathrm{wt}$. \% MWCNTs ) along with a reduction in the slope of $G^{\prime}$ at low frequencies is observed (Figures $6 \mathrm{a}$ and b, respectively). These significant increases of $\eta^{*}$ and $G^{\prime}$ at low frequencies indicate a transition from a liquid to solid-like behavior due to formation of a percolated network of MWCNTs in the polymer attributed to well dispersed nanoparticles in the matrix. ${ }^{33}$ Increasing the content of nanoparticles results in increased interactions between nanoparticles (reduction of interparticle distance) and formation of a network. In preliminary experiments, the dispersion of commercially available surface modified MWCNTs, carboxylic and hydroxyl functionalized MWCNTs from Cheap Tubes in PLA were also examined. The untreated MWCNTs demonstrated a more significant increase of $\eta^{*}$. Thus, no functionalized CNTs were used in the continuation of the work. 
The neat PA11 also shows a Newtonian viscosity plateau at lower frequencies and a slight shearthinning behavior at high frequencies, along with a storage modulus increasing as a function of frequency with a slope of 2 on the $\log -\log$ plot (Figures $6 \mathrm{c}$ and $\mathrm{d}$, respectively). Unlike many other grades of polyamide, this grade is thermally stable (less than $10 \%$ increase of $\eta^{*}$ at $200{ }^{\circ} \mathrm{C}$ during $40 \mathrm{~min}$ time sweep tests). The transition from liquid- to solid-like behavior in rheological properties is observed for the nanocomposites based on PA11 at higher MWCNT contents compared to those based on PLA.

(a)

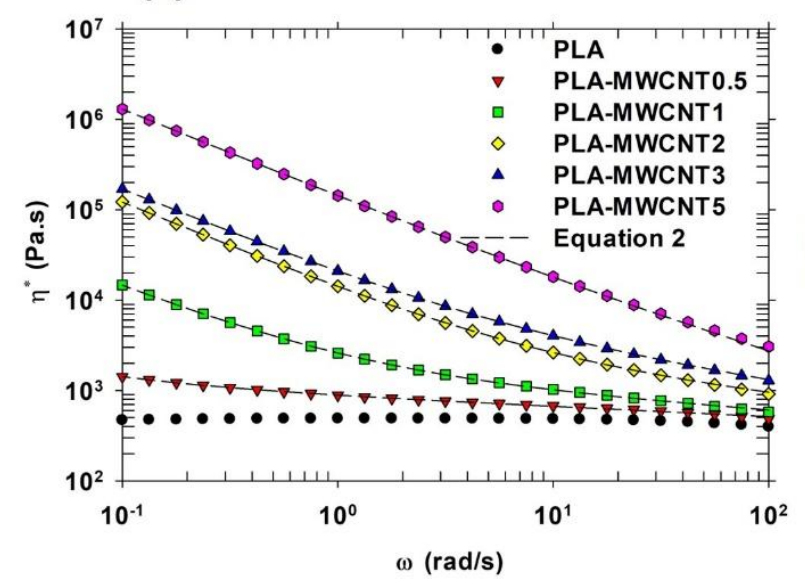

(c)

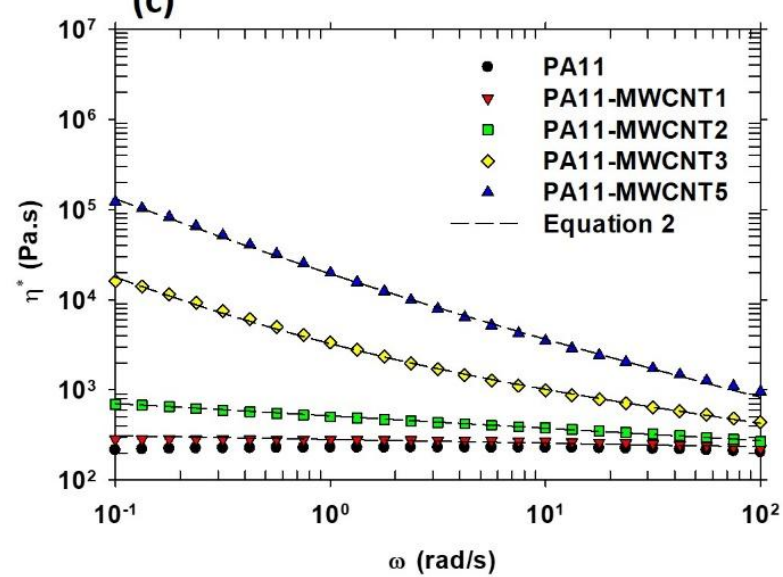

(b)

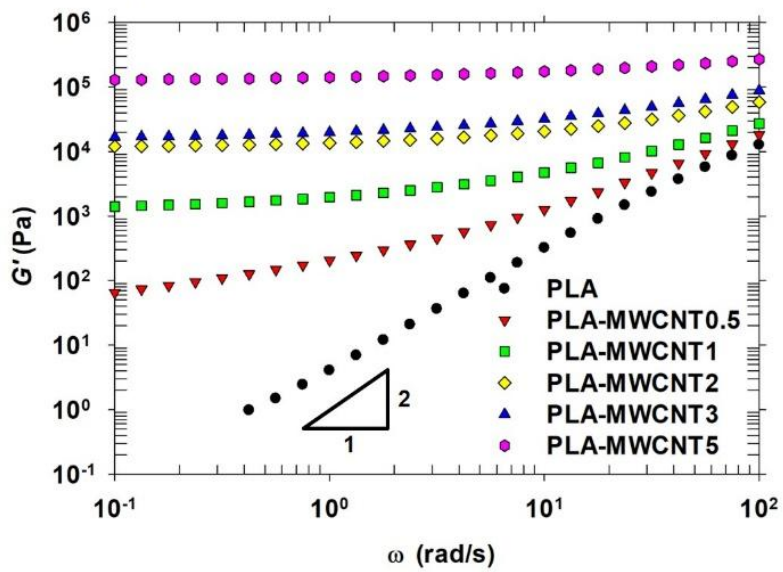

(d)

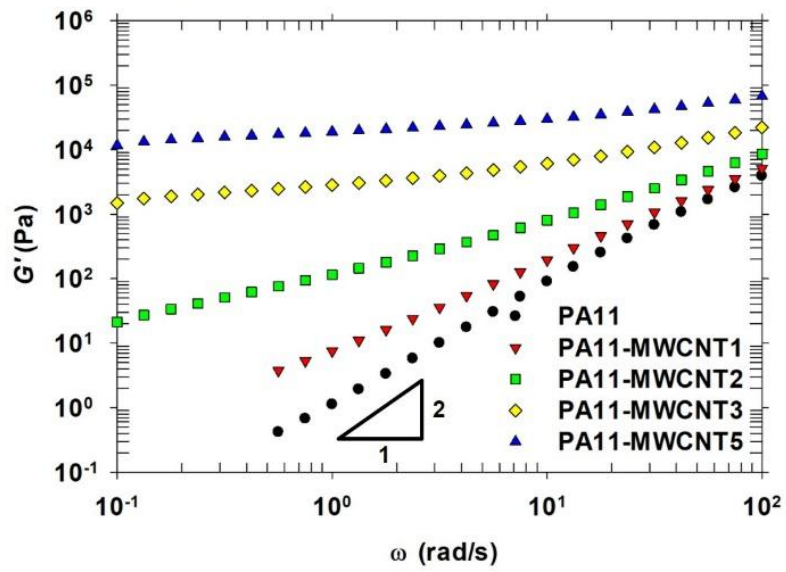

Figure 6. Complex viscosity versus angular frequency of (a) PLA-MWCNT and (c) PA11MWCNT nanocomposites. Storage modulus versus angular frequency of (b) PLA-MWCNT and (d) PA11-MWCNT nanocomposites. 
In PLA an upturn in $\eta^{*}$ at low frequencies is observed by adding $0.5 \mathrm{wt}$. \% MWCNTs while in PA11 at $1 \mathrm{wt}$. \% only a small increase is observed. This indicates a better dispersion of MWCNTs in PLA compared to PA11 due to more interactions between the nanoparticles and polymer chains in PLA than in PA11 and the better affinity of the MWCNTs with PLA compared to PA11, confirming the HSP predictions.

The complex viscosity $\left(\eta^{*}\right)$ and storage modulus $\left(G^{\prime}\right)$ of PLA-DWCNT and PA11-DWCNT nanocomposites are presented in Figures 7a-d. In PLA-DWCNT nanocomposites, adding DWCNTs at lower concentrations reduces $\eta^{*}$ (over the whole frequency range) and $G^{\prime}$ (at higher frequencies) of the nanocomposites below the values of the PLA matrix, which is explained by the degradation of the PLA matrix (Figures 7a and b, respectively). Determining the cause of this observation is out of the scope of this manuscript; however, one potential explanation could be the degradation of PLA caused by residual catalyst in the DWCNTs. ${ }^{29}$ Significant increases in $\eta^{*}$ and $G^{\prime}$ and the transition from liquid- to solid-like behavior are still observed for PLA-DWCNT nanocomposites at CNT contents above $1 \mathrm{wt}$. \%. PA11-DWCNT nanocomposites also exhibit significant increases of $\eta^{*}$ and $G^{\prime}$ at low frequencies with increasing the DWCNTs content above 1 wt. \% indicating the formation of nanoparticles network (Figures 7c and d). For PA11, at 2 wt. $\%$, MWCNTs raise $\eta^{*}$ from 220 to $650 \mathrm{~Pa} . \mathrm{s}$, while DWCNTs raise it to $4500 \mathrm{~Pa} . \mathrm{s}$ (at $0.17 \mathrm{rad} / \mathrm{s}$ ). At 2 wt. \%, MWCNTs raise the PA11 $G^{\prime}$ to 33 vs. 650 Pa for DWCNTs. This is explained by the higher aspect ratio of DWCNTs $v s$. MWCNTs, which results in a lower rheological percolation threshold in nanocomposites containing DWCNTs.

An apparent yield stress also indicates the formation of an interconnected network of anisometric fillers in a polymer matrix..$^{39,40}$ The apparent yield stress for the nanocomposites is obtained by fitting a modified Herschel-Bulkley model (equation 2) to the data of the complex viscosity $v s$. frequency.

$\eta^{*}=\frac{G_{0}^{*}}{\omega}+k\left(\gamma^{0} \omega\right)^{n-1}$

$\sigma_{0}=G_{0}^{*} \gamma^{0}$

where $G_{0}^{*}$ in equation (2) is the magnitude of the complex modulus at the lowest frequency, $\gamma^{0}$ is the maximum strain amplitude in the LVE range for each nanocomposite, $k$ is a constant and $n$ 
is the flow index. Table 3 reports the obtained apparent yield stresses and other parameters from fitting the modified Herschel-Bulkley model to the data. The fits of the model to the data of complex viscosity vs. frequency are also presented in Figures 6a, c and 7a, c. Excellent fits of the modified Herschel-Bulkley model are observed.

(a)

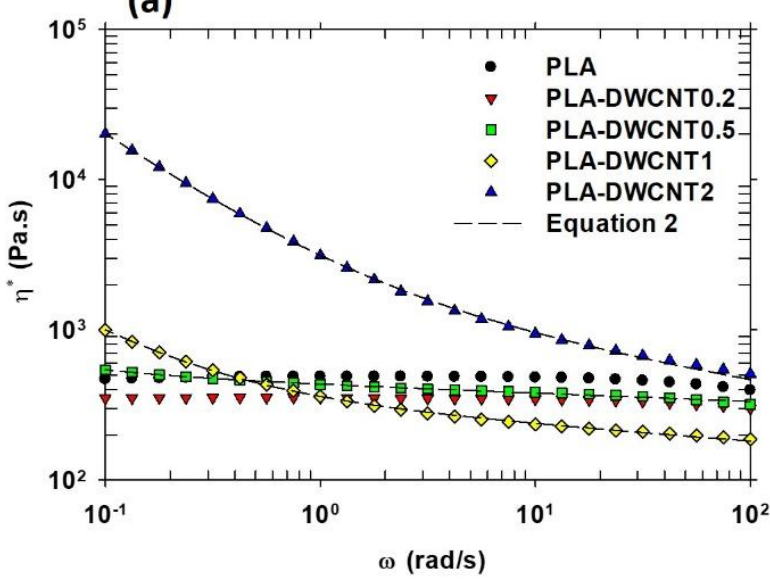

(c)

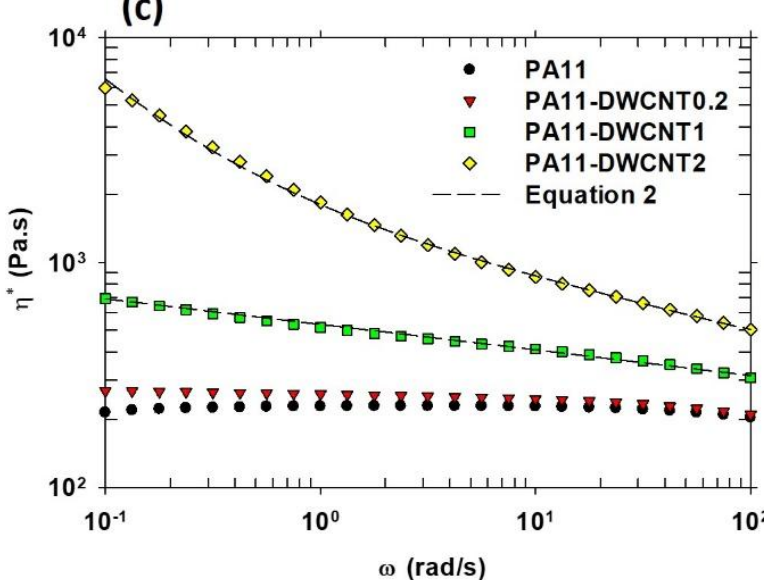

(b)

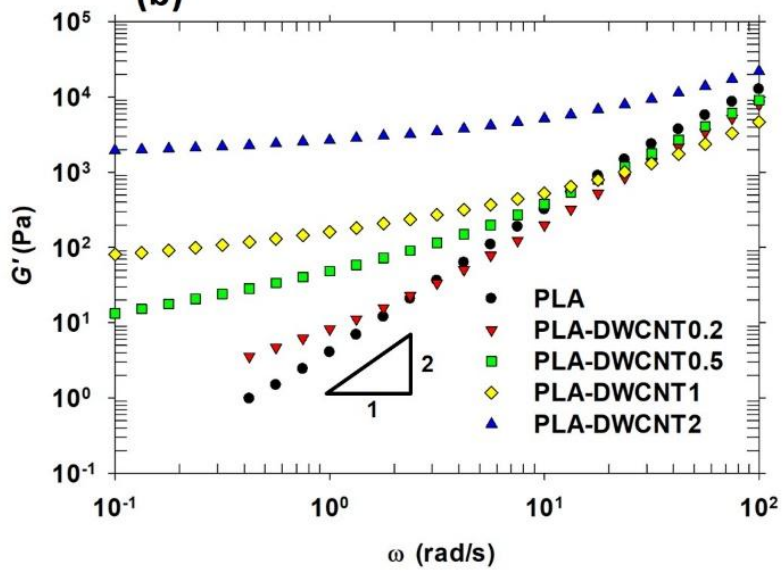

(d)

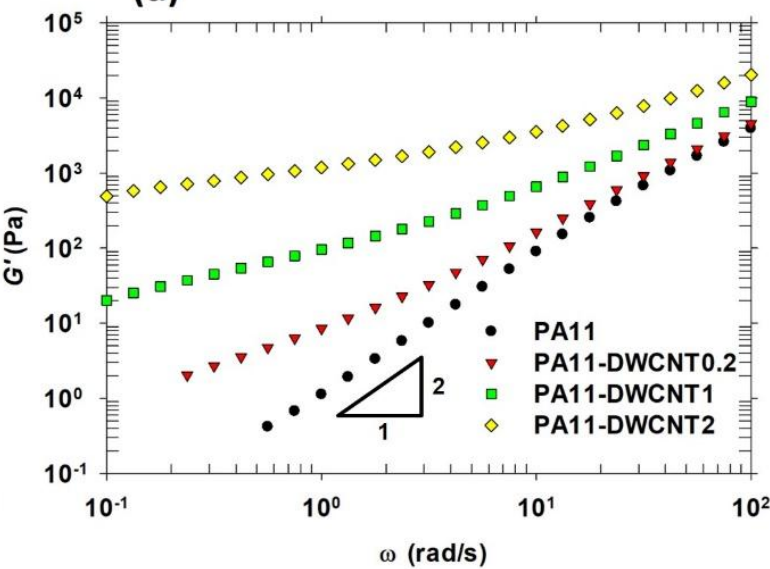

Figure 7. Complex viscosity versus angular frequency of (a) PLA-DWCNT and (c) PA11DWCNT nanocomposites. Storage modulus versus angular frequency of (b) PLA-DWCNT and (d) PA11-DWCNT nanocomposites.

The $\sigma_{0}$ values increase with increasing content of MWCNTs in both PLA and PA11 and the $n$ values decrease as illustrated in Table III The rise in the $\sigma_{0}$ values confirms the stronger particleparticle and particle-polymer interactions resulting in further restricted chain mobility in polymers. The values of the apparent yield stress are larger for the PLA-MWCNT nanocomposites compared to PA11-MWCNT nanocomposites at the same MWCNT loading, 
which reflects the formation of stronger networks of nanoparticles in PLA compared to PA11, due to the better affinity. The values of the apparent yield stress for PLA-DWCNT nanocomposites are affected by the degradation of the matrix and are not presented. Hence, a comparison of the PLA-MWCNT vs. PLA-DWCNT nanocomposites cannot be made.

Table III Modified Herschel-Bulkley model parameter for (a) PLA-MWCNT (b) PA11MWCNT and (c) PA11-DWCNT nanocomposites.

$$
\begin{array}{llll}
\text { CNT wt. } \% & \sigma_{0}(\mathrm{~Pa}) & \boldsymbol{k}\left(\mathrm{Pa} . \mathrm{s}^{n}\right) & n
\end{array}
$$

(a) PLA-MWCNT

\begin{tabular}{llll}
0.5 & 3 & 663 & 0.89 \\
\hline 1 & 64 & 787 & 0.83 \\
\hline 2 & 353 & 1160 & 0.77 \\
\hline 3 & 478 & 1810 & 0.68 \\
\hline 5 & 2420 & 2300 & 0.41
\end{tabular}

(b) PA11-MWCNT

\begin{tabular}{llll}
1 & 0 & 256 & 0.96 \\
\hline 2 & 0 & 318 & 0.86 \\
\hline 3 & 42 & 589 & 0.67 \\
\hline 5 & 190 & 1080 & 0.43
\end{tabular}

(c) PA11-DWCNT

\begin{tabular}{llll}
0.2 & 0 & 247 & 0.97 \\
\hline 1 & 0 & 355 & 0.89 \\
\hline 2 & 17 & 677 & 0.78
\end{tabular}

\section{Rheological percolation}

The rheological percolation threshold is the value of the solid particle content above which the rheological properties increase exponentially. This value is usually determined by fitting an empirical power-law model (equation 4 ) to the $\mathrm{G}^{\prime}$ vs. CNT content data: ${ }^{11}$ 
$\mathrm{G}^{\prime}=\beta_{c G} s\left(\frac{m-m_{c G}}{m_{c G}}\right)^{n} \quad$ for $m>m_{c G}$

where $\beta_{c G}$ and $n$ are power-law constants, $m$ is the CNT content (wt. \%) and $m_{c G}$ is the percolation threshold (wt. \%). The dependence of $G^{\prime}$ on the CNT content is demonstrated in Figure 8. Due to the lack of good fits of this empirical model to the data, approximate values of the rheological percolation threshold are reported. A lower percolation threshold is observed for PLA-MWCNT compared to PA11-MWCNT (below 0.5 wt. \% (0.3 vol. \%) vs. between 2 and 3 wt. \% (0.9 and 1.4 vol. \%), respectively), confirming the better affinity of MWCNTs with PLA. For nanocomposites containing DWCNTs, $G^{\prime}$ values of PLA are affected by the degradation, but the percolation threshold is below 0.5 wt. \% ( 0.3 vol.\%). With PA11, at a specific nanoparticle content, the storage modulus is larger for PA11-DWCNT compared to PA11-MWCNT, due to the higher aspect ratio of the DWCNTs resulting in a lower percolation threshold between 0.2 and 1 wt. \% (0.1- 0.5 vol.\%).
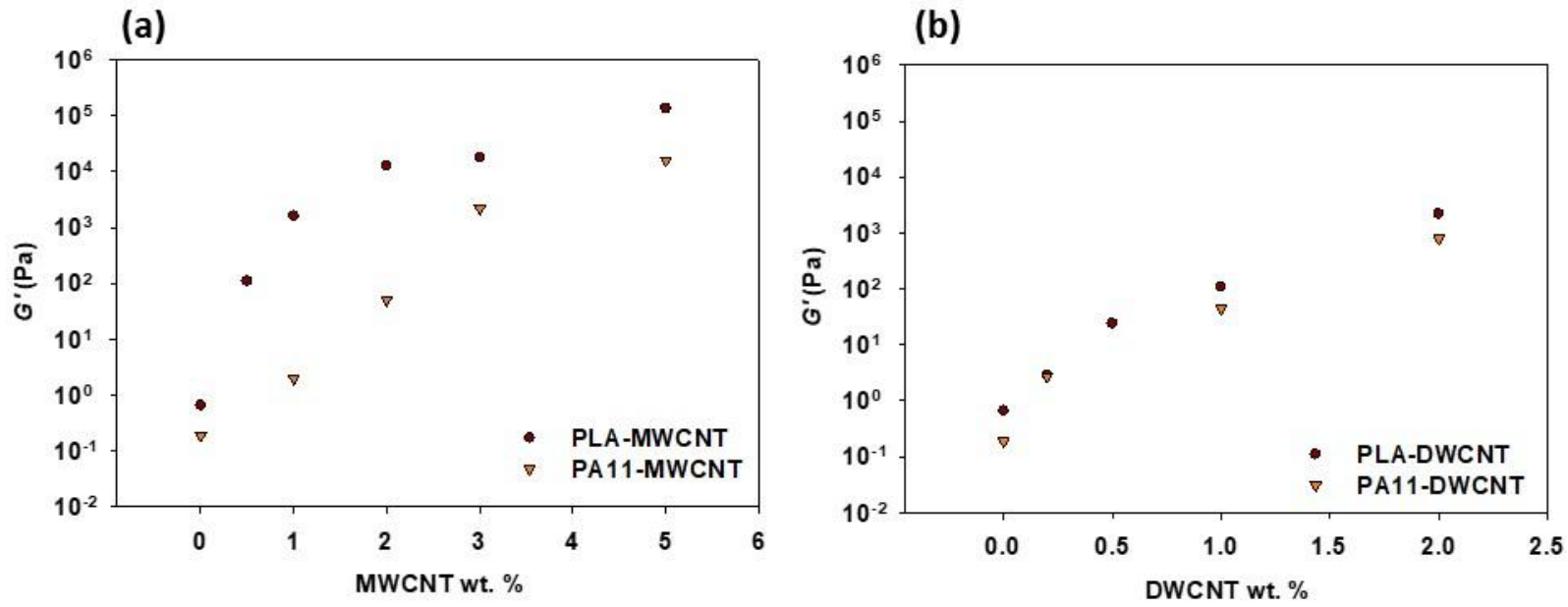

Figure 8. Storage modulus as a function of CNT content (at $0.32 \mathrm{rad} / \mathrm{s}$ ) for nanocomposites containing (a) MWCNTs and (b) DWCNTs.

\section{Electrical conductivity}

The electrical resistivity measurements also provide information about the state of dispersion of electrically conductive nanoparticles in a polymer matrix. The electrical percolation threshold can also be obtained by fitting an empirical power-law model (similar to equation 4) to the data of the electric conductivity $(\sigma) v s$. CNT content. However, due to the lack of good fits of this empirical model, as for the rheological percolation approximate values of the electrical 
percolation threshold are presented. Figure 9 reports the electrical conductivity of PLA and PA11 based nanocomposites. The nanocomposites based on PLA demonstrate higher $\sigma$ values than those based on PA11 at the same loading of CNTs due to the better dispersion, confirming again the better affinity of CNTs with PLA than with PA11. Nanocomposites containing DWCNTs impart higher electrical conductivity in both matrices compared to MWCNTs due to their larger aspect ratio and hence lower electrical percolation threshold. The electrical percolation threshold for PLA based nanocomposites is below 0.5 wt. \% (0.3 vol. \%) for both nanoparticles. The threshold for PA11 containing MWCNTs and DWCNTs is between 3 and 5 wt. \% (1.4 and 2.3 vol. \%), and between 0.2 and 1 wt. \% (0.1 and 0.5 vol. \%), respectively. The highest electrical

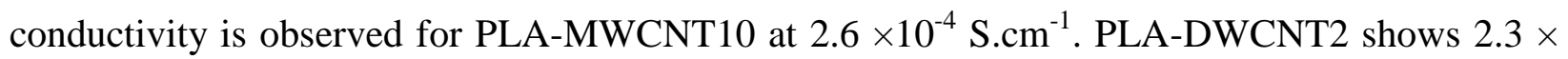
$10^{-5}{\mathrm{~S} . \mathrm{cm}^{-1}}^{-}$. Higher values of $\sigma$ have been reported for nanocomposites containing MWCNTs (especially for PA11), probably due to different degrees of dispersion of nanoparticles. Villmow et $a .^{20}$, obtained a $\sigma$ value of $2 \times 10^{-2} \mathrm{~S} . \mathrm{cm}^{-1}$ at $2 \mathrm{wt} . \%$ MWCNTs in PLA, but the electrical percolation threshold was not much lower than the values obtained in this study for PLA/MWCNT. Abbasi et al. ${ }^{33}$ reported a $\sigma$ value close to $10^{-3} \mathrm{~S} . \mathrm{cm}^{-1}$ at 3 wt. $\%$ MWCNTs in polycarbonate, which increased to about $10^{-2} \mathrm{~S} . \mathrm{cm}^{-1}$ at 16 wt. \% MWCNTs. PA11 nanocomposites containing 2.5 vol $\%$ of MWCNTs had a $\sigma$ value of $10^{-5}{\mathrm{~S} . \mathrm{cm}^{-1}}^{21}$ and $10^{-1}{\mathrm{~S} . \mathrm{cm}^{-1}}^{-1}$ at 6 wt. \% in PA12. ${ }^{41}$

Comparing the rheological and electrical percolation thresholds, similar values below 0.5 wt. \% (0.3 vol. \%) are obtained for the PLA based nanocomposites. The rheological and electrical percolation threshold values of the PA11 based nanocomposites containing DWCNTs are also in the range of 0.2-1 wt. \% (0.1-0.5 vol. \%) while for PA11 based nanocomposites containing MWCNTs, rheological and electrical percolation threshold values are in the range of 2-3 wt. \% (0.9-1.4 vol. \%) and 3-5 wt. \% (1.4-2.3 vol. \%), respectively. A higher threshold for both the electrical and rheological percolations is observed, which could be a result of their worse dispersion compared to the other nanocomposites. Since no accurate values of the percolation thresholds could be determined, it is difficult to draw a definite conclusion on the differences between the rheological and electrical percolation thresholds. Higher threshold values for electrical vs. rheological percolation have been explained by the shorter distance between nanotubes required for electrical conductivity compared to that required for restricting polymer 
chain mobility. Also, the presence of non-metallic nanotubes increases the threshold value for electrical percolation while still affecting the polymer chain mobility. ${ }^{33}$

(a)

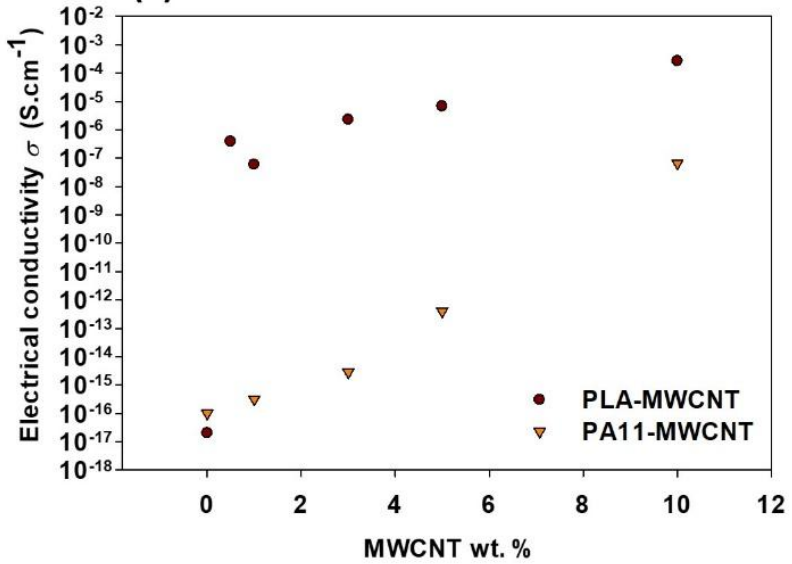

(b)

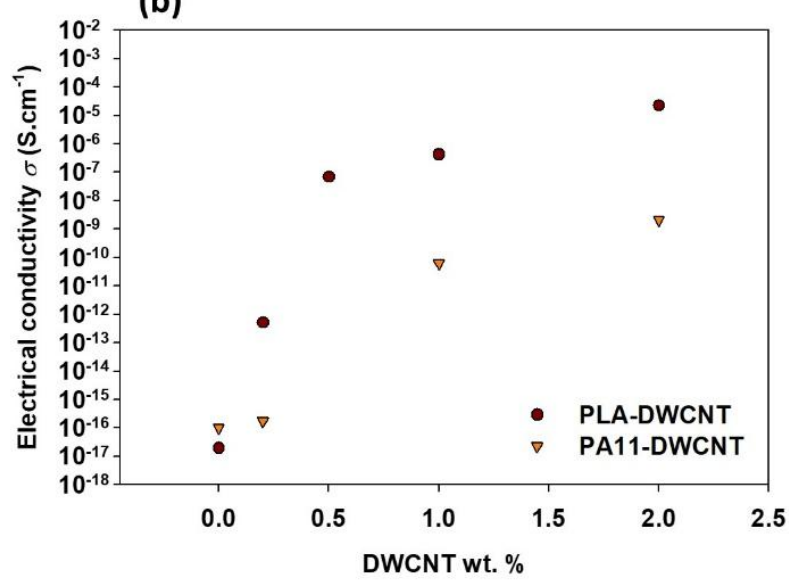

Figure 9. Electrical conductivity as a function of CNT content of nanocomposites containing (a) MWCNTs and (b) DWCNTs.

\section{Dynamic mechanical thermal analysis}

In DMTA we observe increases in storage modulus of both types of nanocomposites with increasing content of CNTs (Figure 10). As expected, the storage modulus decreases with increasing temperature for all nanocomposites as they move from the glassy to the rubbery state. The increases of the storage modulus due to the addition of nanoparticles in the rubbery state are larger than that at the glassy state for all nanocomposites. For example, $E^{\prime}$ of PLA at $25{ }^{\circ} \mathrm{C}$ increases by $20 \%$ (from 1830 to $2206 \mathrm{MPa}$ ) by adding $5 \mathrm{wt} . \% \mathrm{MWCNTs}$, while at $80{ }^{\circ} \mathrm{C}$ it increases by $127 \%$ (from 33 to $76 \mathrm{MPa}$ ). In PA11-MWCNT5 nanocomposites, $E^{\prime}$ increases by $12 \%$ (from 1020 to $1144 \mathrm{MPa})$ in the glassy state $\left(25^{\circ} \mathrm{C}\right)$ while in the rubbery state it increases by $46 \%$ (from 301 to $438 \mathrm{MPa}$ ) by adding 5 wt. \% MWCNTs. Adding 2 wt. \% DWCNTs to PA11 raises $E^{\prime}$ by $9 \%$ and $42 \%$ in the glassy and rubbery states, respectively. 
(a)

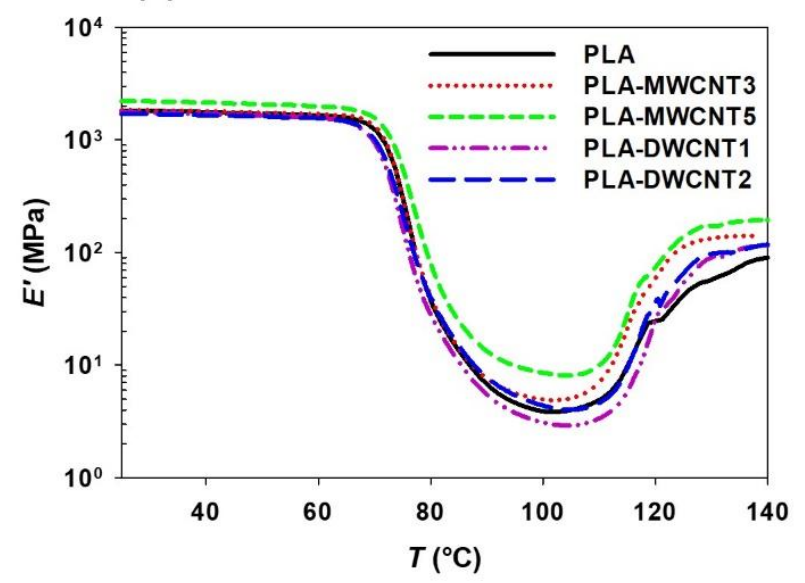

(c)

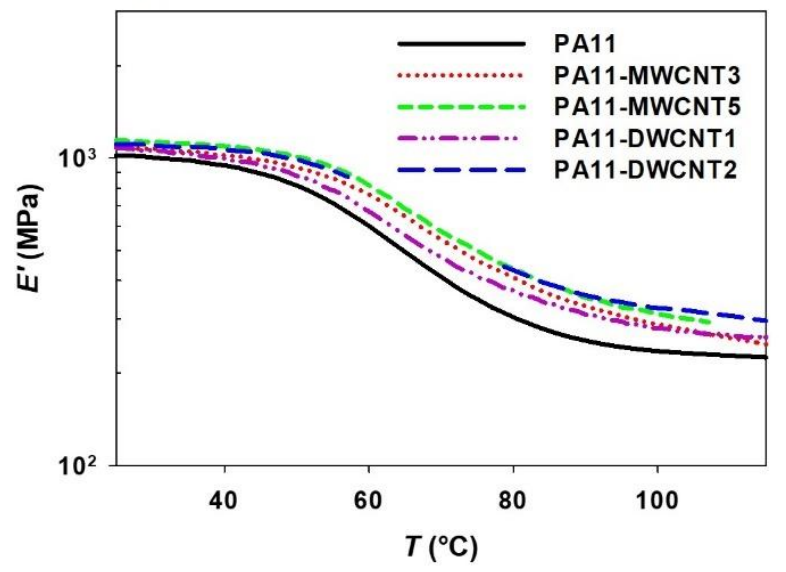

(b)

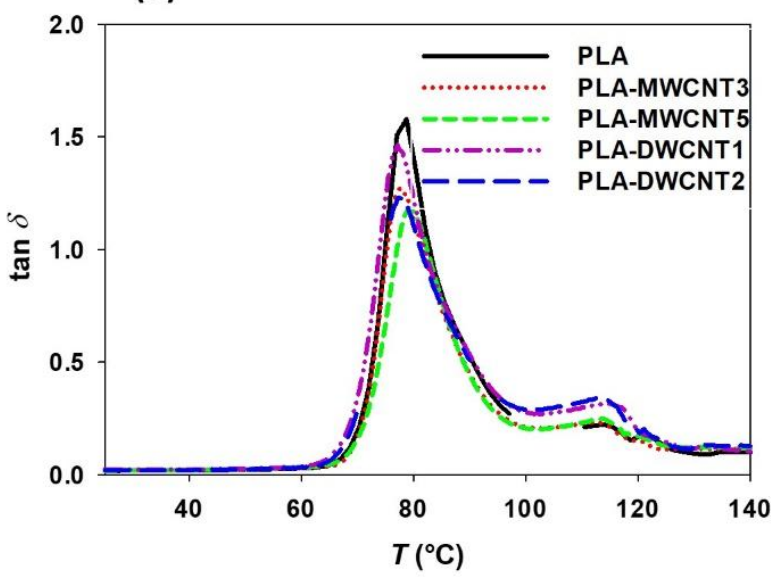

(d)

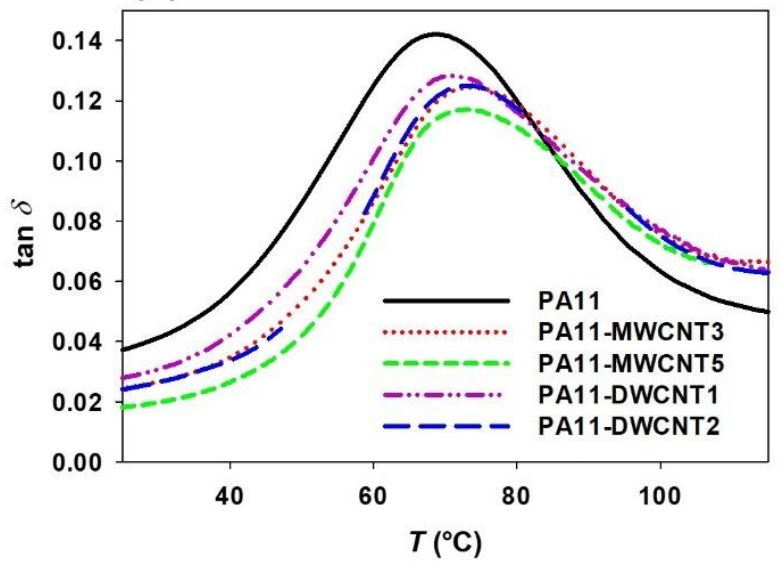

Figure 10. (a and c) Dynamic storage modulus, $E^{\prime}$. (b and d) $\tan \delta$ as a function of temperature for nanocomposites based on PLA and PA11 containing MWCNTs or DWCNTs.

The storage modulus of PLA based nanocomposites increases again at higher temperatures due to the cold crystallization of PLA (Fig. 10a). The onset temperature of the PLA cold crystallization decreases with higher MWCNT content. Adding DWCNTs reduces the storage modulus of PLA, which is due to the degradation of the PLA as observed in rheology.

Figures $10 \mathrm{~b}$ and $\mathrm{d}$ report the loss tangent, $\tan \delta$, where $\delta$ is the phase angle $v s$. temperature. Increasing the content of CNTs in both matrices reduces the area under the $\tan \delta$ curve, indicating the more significant restrained polymer chain mobility due to presence of well dispersed carbon nanotubes. The $\tan \delta$ peak is a characteristic of the glass transition temperature, $T_{g}$, of the nanocomposites. The $T_{g}$ of nanocomposites based on PLA does not change 
significantly, while for those based on PA11, it increases from 68.7 to $74{ }^{\circ} \mathrm{C}$ and $73.7{ }^{\circ} \mathrm{C}$ by adding 5 wt. $\%$ and 2 wt. $\%$ MWCNTs and DWCNTs, respectively. Bhattacharyya et al., ${ }^{25}$ reported a $30 \%$ increase in $E^{\prime}$ from 554 to $728 \mathrm{MPa}$ (at $40{ }^{\circ} \mathrm{C}$ ) and a $90 \%$ increase from 164 to $315 \mathrm{MPa}\left(\right.$ at $80{ }^{\circ} \mathrm{C}$ ) by adding 6 wt. $\%$ SWCNTs to PA12. $T_{g}$ increased from 51.9 to $56.1{ }^{\circ} \mathrm{C}$.

\section{Conclusion}

PLA and PA11 nanocomposites containing various amounts of MWCNTs and DWCNTs were prepared using melt mixing. The dispersion quality of MWCNTs and DWCNTs in PLA and PA11 was evaluated through various characterization techniques. SEM and TEM micrographs revealed that MWCNTs were well dispersed and well distributed in PLA. Some agglomerates were observed in PA11/MWCNT nanocomposites. Rheological characterization confirmed the formation of a percolated network of MWCNTs in both PLA and PA11 by the non-terminal character of $G^{\prime}$ at low frequencies. The rheological percolation thresholds of MWCNTs in PLA were lower compared to those of PA11, indicative of the better affinity of MWCNTs for PLA than for PA11 as pointed out by the HSP predictions. The dispersion of DWCNTs in polymers was more difficult to achieve compared to MWCNTs, due to the larger aspect ratio and the presence of much stronger primary agglomerates and bundles. The SAOS data showed the transition from a liquid- to a solid-like behavior for both nanocomposites containing DWCNTs. The percolation threshold of PLA based nanocomposites was lower compared to that of PA11, however a severe degradation of the PLA was observed when DWCNTs were used. In PA11, DWCNTs formed networks at a lower percolation threshold compared to MWCNTs, due to their higher aspect ratio. The electrical conductivity of nanocomposites based on PLA were higher compared to those based on PA11, confirming the better affinity of CNTs with PLA. DWCNTs enhanced more significantly the electrical conductivity of PLA-based nanocomposites compared to MWCNTs at the same load, due to their higher aspect ratio resulting in lower electrical percolation threshold. Finally, enhanced storage modulus values were observed in DMTA for nanocomposites containing MWCNTs in both matrices, but the improvement was more significant in PLA than in PA11. A decrease in the peak of $\tan \delta$ was also observed with increasing CNT content for both PLA and PA11 nanocomposites, showing the restrained mobility of polymer chains due to the dispersed nanoparticles. PA11 based nanocomposites containing DWCNTs exhibited a similar trend and at lower contents compared to MWCNTs. 


\section{Acknowledgments}

Financial support from the Natural Science and Engineering Research Council (NSERC) of Canada is gratefully acknowledged. The authors also wish to acknowledge the help of Dr. Helia Sojoudiasli and Mr. Matthieu Gauthier for material preparation and processing. Finally, we wish to thank Mr. Jed Randall from NatureWorks for providing the PLA sample and Dr. Francois Bargain from Arkema for providing the PA11 sample.

\section{References}

${ }^{1}$ M. Murariu and P. Dubois, "PLA composites: From production to properties,"Adv. Drug Deliv. Rev. 107, 17 (2016).

${ }^{2}$ P. Venkatraman, A.M. Gohn, A.M. Rhoades, and E.J. Foster, "Developing high performance PA 11/cellulose nanocomposites for industrial-scale melt processing," Composites Part B 174, 106988 (2019).

${ }^{3}$ R.M. Rasal, A.V. Janorkar, and D.E. Hirt, "Poly(lactic acid) modifications,” Prog. Polym. Sci. 35, 338 (2010).

${ }^{4}$ M. Nofar, D. Sacligil, P.J. Carreau, M.R. Kamal, and M.-C. Heuzey, "Poly (lactic acid) blends: Processing, properties and applications” Int. J. Biol. Macromol. 125, 307 (2019).

5 R. Banerjee and S.S. Ray, "An overview of the recent advances in polylactide- based sustainable nanocomposites," Polym. Eng. Sci. 61, 617 (2021).

6 J.-M. Raquez, Y. Habibi, M. Murariu, and P. Dubois, " Polylactide (PLA)-based nanocomposites," Prog. Polym. Sci. 38, 1504 (2013).

${ }^{7}$ M. Kaseem, K. Hamad, F. Deri, and Y.G. Ko, “A review on recent researches on polylactic acid/carbon nanotube composites," Polym. Bull. 74, 2921 (2017). 
${ }^{8}$ K. Kobashi, T. Villmow, T. Andres, and P. Pötschke, "Liquid sensing of melt-processed poly(lactic acid)/multi-walled carbon nanotube composite films," Sens. Actuators B Chem. 134, 787 (2008).

${ }^{9}$ M. Monthioux, P. Serp, E. Flahaut, M. Razafinimanana, C. Laurent, A. Peigney, W. Bacsa, and J.-M. Broto, "Introduction to Carbon Nanotubes," in Springer Handbook of Nanotechnology, edited by B. Bhushan (Springer Berlin Heidelberg, Berlin, Heidelberg, 2010), pp. 47-118.

${ }^{10}$ F. Seichepine, E. Flahaut, and C. Vieu, "A simple and versatile method for statistical analysis of the electrical properties of individual double walled carbon nanotubes," Microelectron. Eng. 88, 1637 (2011).

${ }^{11}$ M. Moniruzzaman and K.I. Winey, "Polymer nanocomposites containing carbon nanotubes," Macromolecules 39, 5194 (2006).

12 I. Alig, P. Pötschke, D. Lellinger, T. Skipa, S. Pegel, G.R. Kasaliwal, and T. Villmow, "Establishment, morphology and properties of carbon nanotube networks in polymer melts," Polymer 53, 4 (2012).

${ }^{13}$ N.G. Sahoo, S. Rana, J.W. Cho, L. Li, and S.H. Chan, "Polymer nanocomposites based on functionalized carbon nanotubes,” Prog. Polym. Sci. 35, 837 (2010).

14 J. Ramontja, S.S. Ray, S.K. Pillai, and A.S. Luyt, "High-performance carbon nanotubereinforced bioplastic,” Macromol. Mater. Eng. 294, 839 (2009).

${ }^{15}$ W.-Y. Lin, Y.-F. Shih, C.-H. Lin, C.-C. Lee, and Y.-H. Yu, J. "The preparation of multiwalled carbon nanotube/poly(lactic acid) composites with excellent conductivity," Taiwan Inst. Chem. Eng. 44, 489 (2013). 
${ }^{16}$ D. Wu, L. Wu, M. Zhang, and Y. Zhao, "Viscoelasticity and thermal stability of polylactide composites with various functionalized carbon nanotubes," Polym. Degrad. Stab. 93, 1577 (2008).

${ }^{17}$ D. Wu, L. Wu, W. Zhou, Y. Sun, and M. Zhang, "Relations between the aspect ratio of carbon nanotubes and the formation of percolation networks in biodegradable polylactide/carbon nanotube composites,” J. Polym. Sci. B Polym. Phys. 48, 479 (2010).

${ }^{18}$ C.-S. Wu and H.-T. Liao, "Study on the preparation and characterization of biodegradable polylactide/multi-walled carbon nanotubes nanocomposites," Polymer 48, 4449 (2007).

${ }^{19}$ C. Li, J. Guo, T. Jiang, X. Zhang, L. Xia, H. Wu, S. Guo, and X. Zhang, "Extensional flowinduced hybrid crystalline fibrils (shish) in CNT/PLA nanocomposite," Carbon 129, 720 (2018).

${ }^{20}$ T. Villmow, P. Pötschke, S. Pegel, L. Häussler, and B. Kretzschmar, "Influence of twin-screw extrusion conditions on the dispersion of multi-walled carbon nanotubes in a poly(lactic acid) matrix" Polymer 49, 3500 (2008).

${ }^{21}$ Y. Huang, L. Tan, S. Zheng, Z. Liu, J. Feng, and M.-B. Yang, "Enhanced dielectric properties of polyamide 11/multi-walled carbon nanotubes composites,” J. Appl. Polym. Sci. 132, (2015).

${ }^{22}$ H. Ha, S.C. Kim, and K. Ha, "Morphology and properties of polyamide/multi-walled carbon nanotube composites,” Macromol. Res. 18, 660 (2010).

${ }^{23}$ G.R. Kasaliwal, T. Villmow, S. Pegel, and P. Pötschke, "Influence of material and processing parameters on carbon nanotube dispersion in polymer melts," in Polymer-Carbon Nanotube Composites, edited by T. McNally and P. Pötschke (Woodhead Publishing, 2011), pp. 92-132.

${ }^{24}$ F.H. Gojny, M.H.G. Wichmann, B. Fiedler, and K. Schulte, "Influence of different carbon nanotubes on the mechanical properties of epoxy matrix composites - A comparative study," Compos. Sci. Technol. 65, 2300 (2005). 
25 A.R. Bhattacharyya, P. Pötschke, M. Abdel-Goad, and D. Fischer, "Effect of encapsulated SWNT on the mechanical properties of melt mixed PA12/SWNT composites," Chem. Phys. Lett. 392, 28 (2004).

${ }^{26}$ S. Barrau, P. Demont, A. Peigney, C. Laurent, and C. Lacabanne, "DC and AC Conductivity of Carbon Nanotubes-Polyepoxy Composites. Macromolecules," Macromolecules 36, 5187 (2003).

${ }^{27}$ A. Bassil, P. Puech, G. Landa, W. Bacsa, S. Barrau, P. Demont, C. Lacabanne, E. Perez, R. Bacsa, E. Flahaut, A. Peigney, and C. Laurent, "Spectroscopic detection of carbon nanotube interaction with amphiphilic molecules in epoxy resin composites,” J. Appl. Phys. 97, 034303 (2005).

${ }^{28}$ V. Tishkova, G. Bonnet, P. Puech, P. Demont, E. Flahaut, and W.S. Bacsa, "Dispersing carbon nanotubes in polymer nanocomposites: detecting individually dispersed tubes," in NSTINanotech 2011 (2011).

${ }^{29}$ E. Flahaut, R. Bacsa, A. Peigney, and C. Laurent, "Gram-scale CCVD synthesis of doublewalled carbon nanotubes," Chem. Commun. 1442 (2003).

${ }^{30}$ H.T. Ham, Y.S. Choi, and I.J. Chung, “An explanation of dispersion states of single-walled carbon nanotubes in solvents and aqueous surfactant solutions using solubility parameters," J. Colloid Interface Sci. 286, 216 (2005).

31 A.O. Borode, N.A. Ahmed, and P.A. Olubambi, "Surfactant-aided dispersion of carbon nanomaterials in aqueous solution” Phys. Fluids 31, 071301 (2019).

${ }^{32}$ National Institute of Health, USA (n.d.).

${ }^{33}$ S. Abbasi, P.J. Carreau, A. Derdouri, and M. Moan, "Rheological properties and percolation in suspensions of multiwalled carbon nanotubes in polycarbonate," Rheol. Acta 48, 943 (2009). 
${ }^{34}$ C.M. Hansen, Hansen Solubility Parameters: A User's Handbook, Second Edition (CRC Press, 2007).

${ }^{35}$ S.J. Abbott, C.M. Hansen, and Y. H., "Hansen solubility parameters in practice software, ebook, datasets," Available: http://www.hansen-solubility.com (2018).

${ }^{36}$ A. Agrawal, A.D. Saran, S.S. Rath, and A. Khanna, "Constrained nonlinear optimization for solubility parameters of poly(lactic acid) and poly(glycolic acid)—validation and comparison," Polymer 45, 8603 (2004).

${ }^{37}$ S. Detriche, J.B. Nagy, Z. Mekhalif, and J. Delhalle, J. "Surface state of carbon nanotubes and Hansen solubility parameters," Nanosci. Nanotechnol. 9, 6015 (2009).

${ }^{38}$ J.D. Ferry, Viscoelastic Properties of Polymers (John Wiley \& Sons, New York, 1980).

${ }^{39}$ L.A. Utracki, "Flow and flow orientation of composites containing anisometric particles," Polym Compos 7, 274 (1986).

${ }^{40}$ A.V. Shenoy, Rheology of Filled Polymer Systems (Springer Science \& Business Media, 2009).

${ }^{41}$ R. Socher, B. Krause, R. Boldt, S. Hermasch, R. Wursche, and P. Pötschke, "Melt mixed nano composites of PA12 with MWNTs: Influence of MWNT and matrix properties on macrodispersion and electrical properties," Compos. Sci. Technol. 71, 306 (2011). 